\title{
The Effects of Selling Complements and Substitutes on Consumer Willingness to Pay: Evidence from Laboratory Experiments ${ }^{\text {a,b }}$
}

\author{
Matthew Rousu (assistant professor, Susquehanna University, Selinsgrove, PA 17870), \\ Robert H. Beach (research economist, RTI International, Research Triangle Park, NC 27709), \\ Jay R. Corrigan (assistant professor, Kenyon College, Gambier, OH 43022).
}

Canadian Journal of Agricultural Economics, forthcoming

JEL codes: C91, D44

Key words: auctions, complements, consumer demand, demand flexibilities, inverse elasticities, laboratory experiments, substitutes.

${ }^{a}$ Corresponding author: Matthew Rousu, Susquehanna University, Selinsgrove, PA 17870, phone: 570-372-4186, e-mail: rousu@susqu.edu.

${ }^{\mathrm{b}}$ The authors thank Jayson Lusk for helpful comments on an earlier draft of this article; and Daniel Monchuk, T.J. Devine, and Silvia Secchi for their assistance in conducting the experiments. Partial funding for this study was provided by the Department of Economics at Iowa State University. 


\title{
The Effects of Selling Complements and Substitutes on Consumer Willingness to Pay: Evidence from Laboratory Experiments
}

\begin{abstract}
Basic economic theory predicts that a consumer's willingness to pay for a good is affected by the availability of complements and substitutes. In an auction setting, this theory implies that the presence of complements would increase bid prices for a good, while the presence of substitutes would decrease bid prices for a good. We designed an experiment that allows the calculation of inverse elasticities, the inverse-demand equivalent of conventional price elasticities. Our results show that the availability of complementary and substitute products affects bids in the expected directions. This finding has important implications for researchers who design experimental auctions.
\end{abstract}

\section{Introduction}

One of economic theory's basic predictions is that consumer demand is affected by the availability of substitutes or complements. In the context of auctions, this prediction implies that the bids submitted for a good should increase when auction participants also have the chance to win a complementary good, and that these bids should decrease when they also have the chance to win a substitute good. ${ }^{1}$ But, depending on the circumstances, researchers who use experimental auctions in consumer demand studies may only be interested in estimating the value of a good in isolation, and therefore wish to avoid the confounding effects introduced by complements and substitutes. Experimental economists have used several methods when collecting bids on multiple products. Many researchers eliciting bids for several related products have done so with the understanding that only one of the products being bid on will actually be 
sold (e.g., Roosen et al., 1998, Rousu et al. 2005). An alternative some researchers have used is allowing for the possibility that a participant may win more than one good, being careful to make sure that those goods are unrelated (e.g., Rousu et al., 2004). Yet another alternative is to allow participants to win multiple goods that are clearly complements or substitutes for one another (e.g., Hoffman et al., 1993; Noussair et al., 2002; Umberger et al., 2002; Noussair et al., 2004). This diversity in methodology underscores the importance of better understanding the role complements and substitutes play in the experimental marketplace.

While economic theory predicts auction participants will change their bids in the presence of complements or substitutes, we know of only one experimental study that has addressed this issue. List and Lucking-Reiley (2000) examine sales of multiple units that were identical (i.e., perfect substitutes) and find that consumers participating in a demand-revealing multi-unit Groves-Clark auction on average submit lower bids for the second unit than for the first. However, no research has examined the impact that selling complements or non-identical substitutes will have on bids submitted in experimental auctions. This lack of emphasis on complements and substitutes is likely due in part to experimental economists' neglect of (inverse) elasticities. One of the most common methods that researchers use to determine whether products are complements or substitutes is the examination of the cross-price elasticity coefficients.

This paper contributes to the literature in two important ways. First, we use a demand revealing experimental design for auctions of three commonly consumed food products to test if consumers change their bidding behavior when they may win multiple products that are complements or substitutes. Second, to assist in estimating the effects of complements and substitutes, our experimental design allows us to estimate inverse elasticities (also known as 
demand flexibilities). To our knowledge, this is the first paper to estimate inverse elasticities using experimental auctions. We estimate these inverse elasticities using a logarithmic specification. Given the fundamental role of elasticities in economic analysis, we hope this paper will help expand the use of inverse elasticities in experimental auctions. Given the explosion of experimental auctions that sell multiple units, this paper provides timely insight into an issue that is often overlooked by experimental economists.

\section{Experimental Design}

Participants bid on combinations of the following three food products in a series of 25 rounds: a 16-ounce jar of salsa, an 8-ounce bag of plain-labeled tortilla chips, and an 8-ounce bag of tortilla chips labeled "Made in America from American Ingredients." We chose these specific products because we believed it was likely that the participants would be familiar with them. The labels were kept basic to avoid the potential of a label's design affecting bids and confounding our results. By having participants bid in an auction where goods are actually purchased by the winning bidders rather than collecting information on stated willingness to pay (WTP) from a hypothetical survey, participants face greater incentives to accurately reveal their preferences.

We used two different auction mechanisms that are widely used in the literature, both of which are demand revealing (i.e., bidding one's true value is a weakly dominant strategy). In the first treatment, participants bid on goods using the second-price, sealed-bid auction (Vickrey, 1961). In the second treatment, participants bid on goods using the random $n$ th-price auction (Shogren et al., 2001). In second-price, sealed-bid auctions, each participant submits a sealed bid for a product. The auction monitor sorts the bids from highest to lowest and the highest bidder wins the auction and pays the second highest bid price for the product. The random $n$ th- 
price auction differs only in that the monitor randomly selects a number between 2 and $N$ (where $N$ is the number of participants), and the bid price corresponding to that number becomes the $n$th price. The $n-1$ bidders who submitted bids higher than the $n$th price then purchase the product paying the randomly selected $n$th price. ${ }^{2}$

The rationale behind both mechanisms is that bidders have incentives to truthfully reveal their WTP because the amount they bid has been separated from the amount they would pay to purchase the product if they are a winning bidder. Therefore, they do not have incentives to underbid their actual valuation to reduce the price paid if they are the winning bidder. Neither do they have incentives to overbid and risk winning the product at a higher price than their private valuation. However, in a second-price auction, low-value bidders that never expect to win may become disengaged and may not truthfully reveal their WTP. With the random $n$ th-price mechanism, every bidder has a chance of winning in every round and faces incentives to bid truthfully regardless of their valuation. Thus, random $n$ th-price auctions offer advantages for ascertaining individual WTP when there are bidders that know their WTP is far below the market-clearing price (Shogren et al., 2001). Because the choice of auction mechanism has been found to affect bidding behavior (Lusk, Feldkamp, and Schroeder, 2004), we varied the auction mechanism to examine the effects on bids.

These auction mechanisms were implemented following standard experimental auction protocols (e.g., Shogren et al., 1994) that help ensure participants understand procedures, remain engaged in the experiment, and truthfully reveal information. While we followed standard experimental auction protocols for second-price and $n$ th-price auctions, we made several refinements to enhance our experimental design. First, we did not post market prices for products, as recent evidence indicates that experimental participants can be influenced by a 
"posted-price" effect (Corrigan and Rousu, 2006). Second, we randomized the order of the rounds across participants. Doing so ensured that the order of bidding did not systematically influence our results. ${ }^{3}$ Third, we sold multiple units of multiple commodities across rounds, thus allowing us to estimate inverse elasticities. Finally, to ensure that our results were not an artifact of the auction mechanism used, we varied the auction mechanism across treatments. This allows us to test whether the results were dependant upon the auction mechanism used.

Ninety-four undergraduate students took part in this study. ${ }^{4}$ All of these students were enrolled in Principles of Economics courses at Iowa State University. While this sample was relatively homogenous, there were some demographic differences across participants that could potentially affect their bids. These characteristics are summarized in table 1.

When participants arrived at the experiment, they completed a consent form and were paid $\$ 5$ for participating. ${ }^{5}$ Each participant was also assigned an I.D. number in order to maintain anonymity. All bid sheets included this I.D. number, so participants' identities would not be revealed in the session. Participants were given both printed and oral instructions on the auction mechanism to be used in that treatment, either the second-price auction or the random $n$ th-price auction. Participants were told that, though they were submitting bids in multiple rounds, only one of those rounds would be randomly chosen as binding. The random selection of only one round as binding is done to allow collection of bids under a variety of product combinations, while avoiding introduction of complicating factors related to participants adjusting their bids to account for the possibility of winning multiple rounds. After reading and hearing the instructions, study participants were given a short quiz on the details of the auction mechanism. They then took part in a series of three practice auctions for various combinations 
of two types of candy bars. The quiz and practice rounds were designed to ensure that participants understood both the auction mechanism and the format of the upcoming rounds.

After the practice rounds, participants were given the chance to examine the three food products for sale in the auction. While participants bid on these products in a series of 25 potentially binding rounds, six of these rounds were designed to explore a separate research question and were not used in the current analysis. ${ }^{6}$ In each of the 19 rounds relevant to our analysis, participants bid on various combinations of the three food products as shown in Table 2. Specifically, they bid on one unit of each product individually, two units of each product individually, and three units of each product individually, as well as different combinations of multiple products. Structuring the experiment in this way allows us to obtain own-price inverse elasticities, because participants are bidding on more than one unit of each product. We can also obtain cross-price inverse elasticities, because participants are bidding on combinations of different products.

After the bidding was completed, the monitor announced the binding round. Next, the auction winners were determined, and any transactions agreed to were carried out. Finally, all participants completed a questionnaire eliciting background and demographic information, which concluded the experiment.

\section{Econometric Model}

Participants in our auctions bid on multiple combinations of the three products. To examine preferences for these products, we first needed to determine the marginal valuations (i.e., WTP) for each additional individual item. When only one unit of a product was available, this task was trivial because we could simply use the bid price submitted. To obtain the marginal valuation for the second unit, we took a participant's total bid for two units and subtracted his bid 
for one unit of the product. ${ }^{7}$ We used a similar process to determine the marginal valuation for the third unit of the commodity. For rounds where multiple products were available and one of them had multiple units, the marginal valuation for units after the first was calculated by subtracting the bid for the same combination of products with one fewer unit of the good. For instance, the marginal value of a second unit of plain-labeled chips in a bundle with one unit of salsa was calculated by subtracting the bid for one unit of chips with one unit of salsa. Although all total bids were constrained to be non-negative, it is possible for a participant's marginal valuation for units after the first to be negative if they bid less for a bundle with more units. For American-labeled chips, plain-labeled chips, and salsa, there were 10, 8, and 20 observations respectively where the marginal valuations were negative. These negative marginal valuations may be due to participant unwillingness to carry a second or third unit home from the experimental auction.

In most competitive markets, quantity demanded by an individual consumer can reasonably be characterized as a function of price (among other explanatory variables), i.e., consumers face a fixed market equilibrium price and must then determine the quantity they are willing to purchase at that price. In an auction framework, however, price is a function of quantity, given that participants face a fixed quantity available for purchase and must then determine the price they are willing to pay. Because of this feature, we estimate the inverse demand for these products. Thus, our measures of price responsiveness are inverse elasticities rather than elasticities. Inverse elasticities measure the responsiveness of consumers' marginal valuations to changes in the quantity available, and are analogous to the more familiar priceelasticity measures used in analyzing conventional demand curves. 
The marginal valuations for each of the three products are hypothesized to be dependent on the quantity of the product available and the presence and quantity of complementary or substitutable products. We estimate our models using a log-log specification. ${ }^{8}$ In the case of plain-labeled chips, the model estimated was:

$$
\ln W T P_{p l n}^{i j}=\alpha_{i}+\beta_{p l n} \ln Q_{p l n}^{j}+\beta_{u s a} \ln Q_{u s a}^{j}+\beta_{s a l} \ln Q_{s a l}^{j}+\gamma X_{i}+\varepsilon_{i j}
$$

where $W T P_{p l n}^{i j}$ is participant $i$ 's marginal willingness to pay for plain-labeled chips as part of bundle $j$, the $Q$ variables are the quantities of each product available in bundle $j$, the $\beta$ s are the corresponding coefficients, $X_{i}$ is a vector of demographic characteristics, $\gamma$ is the corresponding vector of coefficients, and $\varepsilon_{i j}$ is the random error term. Here, the $p l n$ subscript refers to plainlabeled chips, the $u s a$ subscript refers to American-labeled chips, and the sal subscript refers to salsa. The equations for the other two products are defined analogously.

An advantage to using logarithmic models when estimating demand equations is that the coefficients represent elasticities. In addition, we expect marginal valuations to be declining with quantity available. However, the natural log of a zero marginal value is undefined. Thus, values of zero were replaced with a very small positive value of $1 / 100^{\text {th }}$ of a penny $(\$ 0.0001) .{ }^{9}$ In addition, when one of the complementary or substitutable products was not available to be bid on (i.e., zero quantity available), we replaced the zero quantities with 0.0001 .

In only one of the 19 rounds were all three products available in positive quantities. To accurately estimate the own marginal WTP for each of the products as shown in equation (1), rounds where the quantity of the own good was zero were not used in estimation. For example, in estimating the equation for marginal WTP for salsa, we only use the observations where there were one, two, or three units of salsa available, not the observations where zero units of salsa were available. ${ }^{10}$ For each equation, there are 10 observations for each participant; therefore, we 
estimated each demand equation using a random effects model to account for unobserved heterogeneity. $^{11}$

\section{Results}

To better understand the impact complements and substitutes have on bidding behavior, we discuss both findings based on summary statistics and tests of bidder behavior as well as the results of our regression models. Summary statistics for marginal valuations for the products are shown in Table 3. As noted above, negative marginal valuations are possible if bidders reduce their (non-negative) total bids for a bundle of a product when the units of the product increase. To better understand how the availability of complements and substitutes could affect marginal valuations, consider equation (2), which would hold in the absence of complements or substitutes or a binding budget constraint:

$$
\operatorname{Bid}(A)+\operatorname{Bid}(B)=\operatorname{Bid}(A+B)
$$

According to equation (2)Error! Reference source not found., if participants place separate bids on products A and B (when they know they cannot win both products), the sum of their bids to purchase both products individually should equal their bid to purchase both products A and B together if there is no complementarity or substitutability between the products. When products are complements, economic theory predicts that the right-hand side of equationError! Reference source not found. (2) will be greater than the left-hand side. When the products are substitutes (including perfect substitutes, i.e., multiple units of the same product), theory predicts that the right-hand side of equation Error! Reference source not found.(2) will be less than the left-hand side.

As shown in Table 3, the mean marginal valuation for each of the three products declines with the number of units available, as expected. Participants placed a premium on American- 
labeled tortilla chips of about 12 to 15 percent relative to plain-labeled tortilla chips, but both decline in marginal value at a similar rate. Table 4 compares the sum of the individual bids for two products with the bids for the pair of products sold together. This comparison allows us to test equation Error! Reference source not found. 2 and provides insight into how bidding behavior changes in the presence of complements or substitutes.

When the two products sold are complements, the bid for the pair of items when sold together is greater than the sum of the bids for each item individually. A one-sided $t$-test shows that these results are statistically significant at the 0.01 level for the American-labeled chips and salsa, and are statistically significant at the 0.04 level for the plain-labeled chips and salsa. ${ }^{12}$ In the case where the two products are substitutes (the two different types of tortilla chips), the bids for the pair of products when sold together is smaller than the sum of the bids for each item individually. This result is statistically significant at the 0.05 level using a one-sided $t$-test (at the 0.01 level using a one-sided Wilcoxon sign-rank test). Our results show that both complementary and substitutable products affect consumer bids in a way that is consistent with economic theory. Further, more than $44 \%$ of participants altered their marginal valuations of individual products when multiple products were available as part of the bundle auctioned. These results have implications for researchers who wish to use experimental auctions to estimate the value of multiple goods. With a large percentage of participants changing their valuations in the presence of complements or substitutes, researchers who sell related products in an experimental auction run the risk of biasing their results either upward or downward.

The results of our conditional models are shown in tables 5 through 7 . Table 5 shows the results of the regression examining the bid price for the bag of plain-labeled tortilla chips. ${ }^{13}$ The coefficients for the log of the quantities available are of most interest in this analysis because 
these coefficients are the inverse elasticities. The demographic variables included were not significant other than a dummy variable for white participants, who had lower marginal valuations than those that were non-white. The own-quantity inverse elasticity is approximately -1.1 , which indicates that a $10 \%$ increase in the quantity of tortilla chips available would cause consumers to bid approximately $11 \%$ less. ${ }^{14}$

The cross-quantity inverse elasticities show how a change in the quantity of Americanlabeled chips or salsa available changes the bid price for plain-labeled tortilla chips. The crossquantity inverse elasticity for American-labeled tortilla chips is approximately zero. The crossquantity inverse elasticity for salsa on the price of plain-labeled tortilla chips is small, 0.06 , but is statistically significant. This relationship indicates that a $10 \%$ increase in the availability of salsa would yield a $0.6 \%$ increase in the bid prices for plain-labeled tortilla chips, thereby indicating that the consumers in the experiment considered tortilla chips and salsa complements, as expected.

Tables 6 and 7 show the demands for the American-labeled chips and the jar of salsa, respectively. The own-quantity inverse elasticity for American-labeled tortilla chips is close to 1 , while the own-quantity inverse elasticity for the jar of salsa is approximately -2 , indicating that the price participants would pay diminishes rapidly with an increase in the quantity sold. This demonstrates that consumer valuation is more sensitive to the quantity of salsa available than it is for chips, The cross-quantity inverse elasticities for American-labeled tortilla chips are similar to those for the plain-labeled tortilla chips, in that the cross elasticities for the Americanlabeled tortilla chips and the jar of salsa are small but display the expected complementary relationship. ${ }^{15}$ None of the participant characteristics had a statistically significant effect on valuations for either American-labeled chips or salsa. 


\section{Conclusion and Significance}

Despite the common use of elasticity estimates in applied economic analysis, experimental auctions are not usually constructed in such a way that meaningful inverse elasticities can be estimated. This paper reports the results of an experimental auction designed to estimate inverse elasticities. We use a log-log specification to estimate WTP and generate inverse elasticities. The estimated inverse elasticities confirmed our unconditional results: when bidding on a given product, participants bid more when also bidding on a complement and bid less when also bidding on a substitute. These findings suggest that value estimates from auctions where participants could possibly win multiple substitute goods may understate the goods' values in isolation. Similarly, auctions where participants could win multiple goods that are complements may overstate WTP for the individual goods.

These results have implications for the design of experimental auctions. Researchers who wish to sell multiple goods should either attempt to ensure that the goods are neither complements nor substitutes (e.g., Huffman et al., 2003) or should explicitly account for these relationships in auction design. For instance, one method is to collect bids on multiple products in different auction rounds and then randomly select one binding round (e.g., Roosen et al., 1998) so that these relationships can be estimated from the multiple rounds of bids submitted. Future research to address how best to estimate demand in the presence of complements or substitutes is warranted. Also, while this paper presents an exploratory attempt at estimating inverse elasticities, much more work could be done with alternative experimental designs to allow for estimating of inverse elasticities using alternative WTP specifications. 


\section{Footnotes}

${ }^{1}$ Ausubel and Cramton (2002) developed a theoretical model that explores this point for substitutes. The FCC's spectrum auctions are an example of a non-experimental auction where participants may bid on many complementary and substitutable items (e.g., see Cramton, 2003).

2 The complete set of instructions given to participants is available from the authors upon request.

${ }^{3}$ For evidence on how ordering matters in experimental auctions, see Huffman et al. (2003).

${ }^{4}$ While 94 students volunteered to participate, only 90 submitted bids in all auction rounds.

${ }^{5}$ Participants were not restricted to using only this $\$ 5$ for purchasing products in the auction, but only six participants placed bids that were greater than $\$ 5$. Participants were only restricted to placing non-negative bids.

${ }^{6}$ (Should this be published, we will provide a citation of the other paper, which has been published. For now, to stay consistent with the double-blind review process, we only provide a short description without the citation). In the other six rounds participants bid to "upgrade" from one unit of a product to two units, or from two units to three units. This was designed to examine how endowments affect bids in experimental auctions. We varied the order of rounds across participants to randomize any potential ordering effects.

${ }^{7}$ Note that in rounds where participants bid on a bundle containing more than one type of product, they wrote down separate WTP figures for each type of product, then summed these to get their total WTP for the bundle. It was this total WTP that was used to determine who won the auction.

${ }^{8}$ We also estimated models using linear specification and a dummy-variable specification (i.e., using dummy variables to represent the presence or absence of a $1^{\text {st }}, 2^{\text {nd }}$, or $3^{\text {rd }}$ unit of the each 
good), both of which generated qualitatively similar results. Results for these alternative specifications can be obtained from the authors.

${ }^{9}$ We also ran regressions with zero bid prices estimated at 0.001 (higher) and 0.00001 (lower). The results were qualitatively similar to the results we report in this paper.

${ }^{10}$ We could have estimated a "choke price" (i.e., the price at which quantity demanded would be zero) and then used all observations. But, because the choke price would have been estimated by the regressions shown in Equations 1 through 3, we saw no advantages to using that method. ${ }^{11}$ We also ran a fixed effects model and found the same qualitative results, which are available from the authors upon request. A Hausman test indicated no significant differences between the fixed and random effects models (Hausman and Taylor, 1981).

${ }^{12}$ A non-parametric Wilcoxon sign-rank test yields similar results, with results significant at the 0.01 and 0.06 level, respectively.

${ }^{13}$ Recall that we used different auction mechanisms for different participants. Statistical tests could not reject the null hypothesis that there was no difference between the bids from participants using the second- and nth-price auction mechanisms. Because the treatments were independent of one another and the bids did not differ significantly, we pool the data across auction mechanisms in our statistical analysis.

${ }^{14}$ We also ran these models correcting for censoring of the dependent variable and found similar results. This is to be expected because approximately $90 \%$ of the bids were greater than zero. ${ }^{15}$ As mentioned earlier, we also estimated inverse elasticities using a dummy variable WTP specification. While these elasticity estimates were of the expected sign, in general they were not significantly different from zero. 


\section{References}

Ausubel, L.M., P. Cramton (2002). "Demand reduction and inefficiency in multi-unit auctions." working paper (University of Maryland).

Corrigan, J.R., M. Rousu. (2006). "Posted Prices and Bid Affiliation: Evidence from Experimental Auctions.” American Journal of Agricultural Economics, 88, November, Pages 1078-1090.

Cramton, P. (2002). “Spectrum auctions.” in: M. Cave, S. Majumdar, and I. Vogelsang, eds., Handbook of Telecommunications Economics (Amsterdam) 605-639.

Hausman, J. A., W.E. Taylor. (1981) “Panel Data and Unobservable Individual Effects.” Econometrica 49, 1377-1398.

Hoffman, E., D. Menkhaus, D. Chakravarti, R. Field., G. Whipple. (1993). "Using Laboratory Experimental Auctions in Marketing Research: A Case Study of New Packaging for Fresh Beef." Marketing Science 12, 318-38.

Huffman, E., J. Shogren, M. Rousu, A. Tegene. (2003). “Consumer Willingness to Pay for Genetically Modified Food Labels in a Market with Diverse Information: Evidence from Experimental Auctions." Journal of Agricultural and Resource Economics 28, 481-502.

Krinsky, I., A.L. Robb. (1986) “On Approximating the Statistical Properties of Elasticities.” Review of Economics and Statistics 68, 715-19

List, J.A., Lucking-Reiley, D. (2000). "Demand Reduction in Multiunit Auctions: Evidence from a Sportscard Field Experiment.” American Economic Review 90, 961-972.

List, J.A., J.F. Shogren. (1999). "Price Information and Bidding Behavior in Repeated Secondprice Auctions." American Journal of Agricultural Economics 81, 942-949.

Noussair, C., Robin, S., Ruffieux, B. (2002). "Do Consumers Not Care About Biotech Foods or 
Do They Just Not Read the Labels?” Economics Letters. 75, 47-53.

Noussair, C., Robin, S., Ruffieux, B. (2004). "Do Consumers Really Refuse to Buy Genetically Modified Food.” The Economic Journal. 114, 102-120.

Roosen, J., Fox, J.A., Hennessy, D.A., Schreiber, A. (1998). “Consumers' Valuation of Insecticide Use Restrictions: An Application to Apples." Journal of Agricultural and Resource Economics. 23, 367-384.

Rousu, M., Huffman, W.E., Shogren, J.F., Tegene, A. (2004). “Estimating the Public Value of Conflicting Information: The Case of Genetically Modified Foods.” Land Economics. $80,125-135$.

Rousu, M., D. Monchuk, J. Shogren, K. Kosa. 2005. “Consumer Perceptions of Labels and the Willingness to Pay for 'Second-Generation' Genetically Modified Products.” Journal of Agricultural and Applied Economics 37: 647-57.

Shogren, J.F., Margolis, M., Koo, C., List, J.A. (2001). “A Random $n$ th-Price Auction.” Journal of Economic Behavior and Organization. 46, 409-421.

Shorgren, J.F., Shin, S.Y., Hayes, D.J., Kliebenstein, J.B. (1994). Resolving Differences in Willingness to Pay and Willingness to Accept. The American Economic Review. 84 (March), 255-270.

Umberger, W.J., Feuz, D.M., Calkins, C.R., Killinger-Mann, K. (2002). “U.S. Consumer Preference and Willingness-to-Pay for Domestic Corn-Fed Beef Versus International Grass-Fed Beef Measured Through an Experimental Auction.” Agribusiness. 18, 491504.

Vickrey, W. (1961). “Counterspeculation, Auctions, and Competitive Sealed Tenders.” Journal of Finance. 16, 8-37. 
Table 1. Characteristics of the Participants

$\begin{array}{llll}\text { Variable } & \text { Definition } & \text { Mean } & \text { St. Dev. } \\ \text { Gender } & =1 \text { if female } & 0.44 & 0.50 \\ \text { Income } & \text { Monthly cash after living expenses } & \$ 233 & 205 \\ \text { Race_White } & =1 \text { if participant is White } & 0.08 & 0.55 \\ \text { GPA } & \text { Cumulative Grade Point Average of Student } & 3.14 & 1.39\end{array}$


Table 2. The Rounds of Bidding

\begin{tabular}{cccc}
\hline Round & $\begin{array}{c}\text { Quantity of Plain- } \\
\text { Labeled Chips }\end{array}$ & $\begin{array}{c}\text { Quantity of American- } \\
\text { Labeled Chips }\end{array}$ & Quantity of Salsa \\
\hline 1 & 1 & 0 & 0 \\
2 & 2 & 0 & 0 \\
3 & 3 & 0 & 0 \\
4 & 0 & 1 & 0 \\
5 & 0 & 2 & 0 \\
6 & 0 & 3 & 0 \\
7 & 0 & 0 & 1 \\
8 & 0 & 0 & 2 \\
9 & 0 & 0 & 3 \\
10 & 1 & 1 & 0 \\
11 & 1 & 0 & 1 \\
12 & 0 & 1 & 1 \\
13 & 2 & 1 & 0 \\
14 & 2 & 0 & 1 \\
15 & 0 & 2 & 1 \\
16 & 1 & 2 & 0 \\
17 & 0 & 1 & 2 \\
18 & 1 & 0 & 1 \\
19 & 1 & 1 & \\
\hline
\end{tabular}


Table 3. Mean Bids ( $\mathrm{N}=94)$

Part A: Bids for 1, 2, and 3 Units of Each Commodity

\begin{tabular}{|c|c|c|c|c|c|}
\hline Product(s) & Mean & Median & $\begin{array}{l}\text { Standard } \\
\text { Deviation }\end{array}$ & Minimum & Maximum \\
\hline $\begin{array}{l}\text { First bag of plain-labeled } \\
\text { chips }\end{array}$ & $\$ 0.51$ & 0.28 & 0.51 & 0.00 & 2.00 \\
\hline $\begin{array}{l}\text { Second bag of plain-labeled } \\
\text { chips }\end{array}$ & $\$ 0.45$ & 0.25 & 0.50 & 0.00 & 2.00 \\
\hline $\begin{array}{l}\text { Third bag of plain-labeled } \\
\text { chips }\end{array}$ & $\$ 0.40$ & 0.25 & 0.77 & -3.00 & 5.00 \\
\hline $\begin{array}{l}\text { First bag of American- } \\
\text { labeled chips }\end{array}$ & $\$ 0.58$ & 0.48 & 0.56 & 0.00 & 2.25 \\
\hline $\begin{array}{l}\text { Second bag of American- } \\
\text { labeled chips }\end{array}$ & $\$ 0.52$ & 0.25 & 0.62 & -0.50 & 2.80 \\
\hline $\begin{array}{l}\text { Third bag of American- } \\
\text { labeled chips }\end{array}$ & $\$ 0.45$ & 0.25 & 0.65 & -3.00 & 2.30 \\
\hline First jar of salsa & $\$ 0.65$ & 0.50 & 0.57 & 0.00 & 2.30 \\
\hline Second jar of salsa & $\$ 0.55$ & 0.36 & 0.62 & -0.20 & 2.50 \\
\hline Third jar of salsa & $\$ 0.40$ & 0.25 & 0.70 & -2.50 & 2.01 \\
\hline
\end{tabular}

Part B: Bids for Combinations of 2 Items

$\begin{array}{llllll}1 \text { bag of plain-labeled chips } & 1.03 & 0.95 & 0.95 & 0 & 4.25\end{array}$ and 1 bag of Americanlabeled chips

$\begin{array}{llllll}1 \text { bag of plain-labeled chips } & 1.24 & 1.00 & 1.10 & 0 & 5.50\end{array}$ and 1 jar of salsa

1 bag of American-labeled

$1.31 \quad 1.00$

1.08

0

5.00

chips and 1 jar of salsa 
Table 4. How Do Bids Change in Bundles of Complements or Substitutes? The Value Is the Bid for the Bundle of Goods Minus the Sum of the Individual Bids for the Products $(\mathrm{N}=94)$.

Products

Plain-labeled chips and jar of salsa

Standard deviation

American-labeled chips and jar of salsa

Standard deviation

Plain-labeled chips and American-labeled chips

Standard deviation

* Statistically significant at the 0.05 level using a one-sided $t$-test.

** Statistically significant at the 0.01 level using a one-sided $t$-test.
Mean Deviation

$0.09 *$

$0.16 * *$

(0.57)

$-0.06 * *$

(0.30) 
Table 5. Random Effects Model: Logarithmic Specification

Dependent variable: $\log$ of bid price for plain-labeled tortilla chips

\begin{tabular}{|c|c|c|c|c|c|}
\hline & (1) & (2) & (3) & (4) & (5) \\
\hline \multirow[t]{2}{*}{ Intercept } & $-1.63 * *$ & -0.29 & -0.41 & 0.91 & 1.08 \\
\hline & $(0.30)$ & $(1.35)$ & $(1.41)$ & $(1.56)$ & (1.64) \\
\hline Log (quantity of plain- & $-1.09 * *$ & $-1.09 * *$ & $-1.09 * *$ & $-1.09 * *$ & $-1.09 * *$ \\
\hline labeled tortilla chips) & $(0.17)$ & $(0.17)$ & $(0.17)$ & $(0.17)$ & $(0.17)$ \\
\hline Log (quantity of American- & 0.00 & 0.00 & 0.00 & 0.00 & 0.00 \\
\hline labeled tortilla chips) & $(0.01)$ & $(0.01)$ & $(0.01)$ & $(0.01)$ & $(0.01)$ \\
\hline \multirow[t]{2}{*}{ Log (quantity of salsa) } & $0.06^{* *}$ & $0.06^{* *}$ & $0.06^{* *}$ & $0.06^{* *}$ & $0.06^{* *}$ \\
\hline & $(0.01)$ & $(0.01)$ & $(0.01)$ & $(0.01)$ & $(0.01)$ \\
\hline \multirow[t]{2}{*}{ Female } & & & 0.12 & 0.11 & 0.12 \\
\hline & & & $(0.58)$ & $(0.58)$ & $(0.58)$ \\
\hline \multirow[t]{2}{*}{ Race: white } & & & & $-1.38 *$ & $-1.40 *$ \\
\hline & & & & $(0.61)$ & $(0.61)$ \\
\hline \multirow[t]{2}{*}{ Log (income) } & & -0.27 & -0.26 & -0.33 & -0.31 \\
\hline & & $(0.27)$ & $(0.28)$ & $(0.27)$ & $(0.27)$ \\
\hline \multirow[t]{2}{*}{ GPA } & & & & & -0.07 \\
\hline & & & & & $(0.20)$ \\
\hline
\end{tabular}

Note: Numbers in parentheses are standard errors.

* Statistically significant at the 0.05 level.

** Statistically significant at the 0.01 level. 
Table 6. Random Effects Model: Logarithmic Specification

Dependent variable: log of bid price for American-labeled tortilla chips

\begin{tabular}{|c|c|c|c|c|c|}
\hline & (1) & (2) & (3) & (4) & $(5)$ \\
\hline \multirow[t]{2}{*}{ Intercept } & $-1.49 * *$ & -0.39 & -0.43 & 0.61 & 0.66 \\
\hline & $(0.29)$ & $(1.26)$ & $(1.38)$ & $(1.47)$ & $(1.54)$ \\
\hline Log (quantity of plain- & 0.00 & 0.00 & 0.00 & 0.00 & 0.00 \\
\hline labeled tortilla chips) & $(0.01)$ & $(0.01)$ & $(0.01)$ & $(0.01)$ & $(0.01)$ \\
\hline Log (quantity of American- & $-1.00 * *$ & $-1.00 * *$ & $-1.00 * *$ & $-1.00 * *$ & $-1.00 * *$ \\
\hline labeled tortilla chips) & $(0.17)$ & $(0.17)$ & $(0.17)$ & $(0.17)$ & $(0.17)$ \\
\hline \multirow[t]{2}{*}{ Log (quantity of salsa) } & $0.05 * *$ & $0.05 * *$ & $0.05 * *$ & $0.05^{* *}$ & $0.05 * *$ \\
\hline & $(0.015)$ & $(0.002)$ & $(0.002)$ & $(0.02)$ & $(0.02)$ \\
\hline \multirow[t]{2}{*}{ Female } & & & 0.03 & 0.02 & 0.03 \\
\hline & & & $(0.55)$ & $(0.54)$ & $(0.55)$ \\
\hline \multirow[t]{2}{*}{ Race: white } & & & & -1.08 & -1.08 \\
\hline & & & & $(0.60)$ & $(0.60)$ \\
\hline \multirow[t]{2}{*}{ Log (income) } & & -0.22 & -0.22 & -0.27 & -0.27 \\
\hline & & $(0.25)$ & $(0.26)$ & $(0.25)$ & $(0.26)$ \\
\hline \multirow[t]{2}{*}{ GPA } & & & & & -0.07 \\
\hline & & & & & $(0.20)$ \\
\hline
\end{tabular}

Note: Numbers in parentheses are standard errors.

* Statistically significant at the 0.05 level.

** Statistically significant at the 0.01 level. 
Table 7. Random Effects Model: Logarithmic Specification

Dependent variable: Log of bid price for salsa

\begin{tabular}{|c|c|c|c|c|c|}
\hline & (1) & (2) & (3) & (4) & (5) \\
\hline \multirow[t]{2}{*}{ Intercept } & $-1.24 * *$ & -0.99 & -0.44 & 0.53 & 0.31 \\
\hline & $(0.28)$ & $(1.24)$ & $(1.34)$ & $(1.43)$ & $(1.50)$ \\
\hline Log (quantity of plain- & 0.02 & 0.02 & 0.02 & 0.02 & 0.02 \\
\hline labeled tortilla chips) & $(0.02)$ & $(0.02)$ & $(0.02)$ & $(0.02)$ & $(0.02)$ \\
\hline Log (quantity of American- & 0.01 & 0.01 & 0.01 & 0.00 & 0.00 \\
\hline labeled tortilla chips) & $(0.02)$ & $(0.02)$ & $(0.02)$ & $(0.02)$ & $(0.02)$ \\
\hline \multirow[t]{2}{*}{ Log (quantity of salsa) } & $-1.94 * *$ & $-1.94 * *$ & $-1.94 * *$ & $-1.94 * *$ & $-1.94 * *$ \\
\hline & $(0.19)$ & $(0.19)$ & $(0.19)$ & $(0.19)$ & $(0.19)$ \\
\hline \multirow[t]{2}{*}{ Female } & & & -0.56 & -0.57 & -0.58 \\
\hline & & & $(0.53)$ & $(0.53)$ & $(0.53)$ \\
\hline \multirow[t]{2}{*}{ Race: white } & & & & -1.01 & -0.98 \\
\hline & & & & $(0.55)$ & $(0.56)$ \\
\hline \multirow[t]{2}{*}{ Log (income) } & & -0.05 & -0.11 & -0.17 & -0.17 \\
\hline & & $(0.24)$ & $(0.25)$ & $(0.25)$ & $(0.25)$ \\
\hline \multirow[t]{2}{*}{ GPA } & & & & & 0.10 \\
\hline & & & & & $(0.18)$ \\
\hline
\end{tabular}

Note: Numbers in parentheses are standard errors.

* Statistically significant at the 0.05 level.

** Statistically significant at the 0.01 level. 
Appendix - condensed instruction packet given to participants

Welcome! Thank you for choosing to participate in an experiment about economic decision making. In this folder is a packet of information that you will need during the experiment. Once you have looked at a form during the experiment, feel free to go back and examine that form again if need be, but please do not look ahead.

It is very important that you follow the instructions carefully. Also, to ensure accuracy, please do not talk to or try to communicate with other participants.

I would like to emphasize that all information obtained today will be used only for group comparisons. No individual information will be divulged for any reason.

Today we will be conducting auctions for some common food products. In a moment we will give you detailed instructions on how the auctions will work.

You have been paid $\$ 5.00$ for participating in this experiment. That money is yours to do with as you please. If you like, you can keep it and take it home with you at the end of the experiment. You will also be given the chance to spend a portion of it on food items for sale in the auctions we are about to conduct.

Because we are trying to determine values for different products, we again ask that you do not communicate with other participants. If you have any questions, please raise your hand and a monitor will come to you.

\section{How the Auction Works}

Today we will be using what is known as a "2nd price auction." The auction will have four steps:

Step 1 You will be given a chance to inspect the item or items being auctioned off.

Step 2 Each of you will submit a bid by writing your bid on your bid record sheet.

Step 3 The monitor will collect the bids and rank them from highest to lowest.

Step 4 The person who submits the highest bid "wins" the auction and buys the goods at the second highest price submitted. In the case of a tie, the winner will be selected at random.

A simple example will help to clarify things. Suppose ten people (Person A, Person B, Person C, ..., Person J) are bidding to buy a front row ticket to next season's Iowa-Iowa State football game. Their bids are as follows: 
Person A-\$24.50

Person B- $\$ 98.00$

Person C-\$250.00

Person D- $\$ 12.80$

Person E- $\$ 50.00$

Person F- $\$ 1.42$

Person G-\$67.00

Person H- $\$ 34.50$

Person I-\$9.99

Person J-\$10.00

The monitor collects these bids and ranks them from highest to lowest:

$\begin{array}{lll}\text { Rank-ordered bids: } & \text { Person } \mathrm{C}-\$ 250.00 & \text { highest bid } \\ & \text { Person } \mathrm{B}-\$ 98.00 & \\ & \text { Person } \mathrm{G}-\$ 67.00 & \\ & \text { Person } \mathrm{E}-\$ 50.00 \\ & \text { Person H-\$34.50 } \\ & \text { Person } \mathrm{A}-\$ 24.50 & \\ & \text { Person D-\$12.80 } \\ & \text { Person J-\$10.00 } \\ & \text { Person I-\$9.99 } \\ & \text { Person F-\$1.42 } & \end{array}$

Person $\mathrm{C}$ is the highest bidder, so she wins the auction and pays the second highest price in exchange for the ticket. In this case, she buys a ticket for $\$ 98.00$.

In this type of auction, it is always in your best interest to bid exactly what the item being auctioned off is worth to you. You do not want to bid more than your true value because the second highest price might turn out to be more than you are willing to pay for the item. What may not be so obvious is that you do not gain by bidding less than the most you are willing to pay. This is because the winner generally does not pay the amount that he or she bid, but instead pays the price submitted by the second highest bidder.

\section{Short Quiz on Auction Format}

Please complete the following quiz to make sure that you understand the auction format we will be using. The quiz will not be collected. Instead, the monitor will explain the answers once everyone has finished. 
1. The winner of an auction will always have to pay what he or she bid.
a. True
b. False

2. If you have the second highest bid, you win the auction.
a. True
b. False

3. You might pay less than the amount you bid, but you will never pay more than that amount.
a. True
b. False

4. The person who submits the highest bid wins the auction and pays the price submitted by the second highest bidder.
a. True
b. False

5. In this type of auction, it is always in your best interest to bid the maximum amount you are truly willing to pay for the item or items being auctioned off.
a. True
b. False

\section{Practice Rounds}

These 2 rounds will not count, but will serve to illustrate how we will be holding the auction.

Please come to the front of the room to examine the two candy bars available in this auction.

There are two trial rounds, but only one would count, that is only one of the two would be chosen as a binding (valid) round. This will be chosen after you bid in the two rounds.

On the practice bid sheet on the next page, please place a bid for the Nestle Crunch bar in trial round 1.

For trial round 2, please place a bid for both the Nestle Crunch bar and the Butterfinger bar. We ask that you determine the price you would pay for each - by writing the prices next to the good in the shaded area. Then add up the totals in the shaded boxes. This is your total bid for the two products that will be used to compute the bids, should this be the binding (valid) round. 
In trial round 3, you are endowed with (given) a Nestle Crunch bar. You are bidding to go from a Nestle Crunch bar to both a Nestle Crunch bar and a Butterfinger candy bar.

On the practice bid sheet on the next page, please place a bid to upgrade the Nestle Crunch bar to both a Butterfinger and a Nestle Crunch bar candy bar.

Now that bids for all the practice trials have been placed, the monitor will pick up all of the practice trial bid sheets.

Once all the bid sheets are collected, the monitor will select which of the 3 practice rounds would be the binding round

Then, the monitor will write down the highest bids. The highest bidder would win the auction, and pay the $2^{\text {nd }}$ highest price.

Please notice the following two things: (1) Your bid cannot affect the price you will pay if you win the auction. (2) It is in your best interest to bid your true value.

\section{Instructions - Bidding part 1}

Today you will be bidding on three different food items shown at the front of the room. Please take a few moments to come to the front of the room to examine the three products that you will be bidding on in the auctions.

You will be bidding on the three goods, tortilla chips, tortilla chips that are "made in America", and Salsa in various combinations. For example, in one of the trials, you will be bidding on two bags of "made in America" tortilla chips, while in another round you will be bidding on 1 of all three goods.

While there are several trials, only one is going to count as the binding (valid) round.

For the first set of trials, you will be bidding on different combinations of food products. You will submit your bid by writing it on the appropriate line of the bid from on the following page. 
Once again, when there is more than 1 item up for sale, please calculate your total price by determining your bid price for each of the food products, and then adding those up into the gray column on the right hand side.

If there are multiple units of the same product, you may just enter in your total price for those multiple products (for example, if you are bidding in the round for 2 bags of chips, you can enter your total price for the 2 bags, you do not have to enter in how much you would pay for each bag).

Please begin bidding on the products in the first set of 19 rounds

$$
\text { Instructions - Bidding part } 2
$$

The next 6 rounds are conducted in a slightly different way.

In these rounds, you are endowed with a one unit of one of the goods - and you are paying to upgrade to multiple units.

For example, in one of the rounds you are endowed with 1 jar of salsa, and you are paying to go from that, to 1 jar of salsa AND 1 bag of "Made in U.S.A." chips.

Remember only one round in this experiment will count as valid - if it is one of these 6 rounds everybody in the room will be given the one unit of the good listed in the "YOU ARE GIVEN" column, and the person with the highest bid will upgrade to the bundle in the third column.

As before, the top bidder will win the auction and pay the second highest price. 
Determining the winning round and bidder

Now that all of the bid sheets are collected, we will determine which round counts as the binding round.

Now that we have determined the binding round, we will determine who wins the auction. 